\title{
To Promote the Development of the Red River Basin: Background, Conditions and Countermeasures
}

\section{Feng Li, Junyi Chen}

Faculty of Economic and Trade, Haikou College of Economics, Haikou, China

\section{Email address:}

lifeng197053@163.com (Feng Li), cjy95123@vip.qq.com (Junyi Chen)

\section{To cite this article:}

Feng Li, Junyi Chen. To Promote the Development of the Red River Basin: Background, Conditions and Countermeasures. Humanities and Social Sciences. Vol. 3, No. 5, 2015, pp. 225-229. doi: 10.11648/j.hss.20150305.19

\begin{abstract}
In the framework of Chinese ASEAN Free Trade Area, pan area of Honghe River Basin is this framework complements and expands. The Red River mainly flows through the Vietnam Laos, especially between China and vietnam. In international, regional development under the new situation, "the important concept of Pan Red River". Regional overall political and economic situation is stable, to improve traffic conditions, industrial resources complement each other, the practice of regional cooperation to further promote and accelerate the development of the pan in the Red River Valley has a certain foundation and conditions. Honghe River basin to promote the development of pan, pan Red River Valley Economic Development consensus reached; promote regional factor flow, industrial upgrading and transfer; to give full play to the advantages of traffic location, to build China and Southeast Asia Logistics Center; seek the multi polarization of the regional development; strengthen port construction, built in the cooperation zone in the border areas.
\end{abstract}

Keywords: The Red River Basin, the Development Conditions, Deal with

\section{推动泛红河流域发展: 背景、条件与应对}

\section{李峰, 陈俊怡}

经济贸易学院, 海口经济学院, 海南海口, 中国

\section{邮箱}

lifeng197053@163.com（李峰）, cjy95123@vip.qq. com(陈俊怡)

摘要: 在中国-东盟自由贸易区的框架下, 泛红河流域地区是对此框架的补充与拓展。红河主要流经中越老三国, 特别 是中越两国。在国际、区域发展新形势下，“泛红河流域”概念有着重要意义。区域总体的政治经济形势稳定、交通 条件改善、产业资源互补、区域合作实践进一步推进，使加快泛红河流域发展具备了一定基础和条件。推进泛红河流 域发展, 就要达成泛红河流域经济发展共识; 促进区域要素流动、产业升级与转移; 发挥区位交通优势, 打造中国与 东南亚的物流集散地; 寻求多极化的区域发展动力; 加强口岸建设, 建好边境区域合作区。

关键词：泛红河流域，发展条件，应对

\section{1. 引言}

红河是一条国际河流，有人称其为中越人民友好往来、 文化交流、贸易合作、共同繁荣的金色纽带。据有关资料 表述, 红河干流全长大约 1140 公里, 其中500公里在越南,
流经中、老、越三国, 最终流入北部湾。红河流域大约有 16.9 万平方公里, 在中国云南省境内大约 7.674 万平方公 里, 中国广西省境内 0.226 万平方公里, 老挝境内 0.15 万 平方公里, 其余部分位于越南境内。 $[1]$ 从地理上对红河 流域范围的界定, 适应了对红河流域水资源、环境等的联 
合开发和治理的需要。当然, 自然形态上的划分是形成红 河流域经济区域的地理基础。在世界各国追求以经济增长 为核心内容的综合实力提升的压力下, 对于中越两国来说, 红河是中越之间合作的桥梁, 红河流域的意义在于从经济 区域上的划分。泛红河流域地区的发展对于适应经济全球 化与区域化的新竞争, 融入国际区域合作发展的新框架, 构建中国西南地区与东南亚区域发展的新格局都具有重 要意义。

\section{2. 提出 “泛红河流域” 区域发展理念的背景与意 义}

泛红河流域主要指红河流经的中国云南、广西, 越南 和老挝的相关区域, 以及中国西南相邻地区。“泛红河流 域” 的概念, 将红河流域推向更广的区域, 继续打破了 传统流域或区域划分的国别、行政区划限制, 以经济要素 自由流动、产业自由转移为目的, 形成以红河流域地区为 中心的资源互补、产业关联、梯度发展的经济隆起带。当 然, 这一提法有待在实践中进行更深入的研究与论证, 如 具体区域的落实等, 在此只是初步尝试。将泛红河流域地 区纳入了国际区域经济发展视野, 对于中国西南地区、越 南大部分地区乃至东南亚区域经济发展都具有重要意义。

\section{1. 适应经济全球化与区域化新竞争}

经济全球化和区域化是当今世界经济一体化的主要 表征。经济全球化是世界经济活动超越国界的过程, 也是 当代世界经济的重要特征之一, 更是世界经济发展的重要 趋势。经济技术发展水平和环境的制约使得全球化将是一 个长期的过程。[2]经济区域化是地理位置相邻的一些国 家或地区, 通过竞争与合作, 实现区域范围内生产要素的 自由流动和有效配置, 维护各自经济利益的动态过程。经 济区域化与全球化并行不悖, 并以各自独特方式驱动着经 济一体化进程, 进而推动着世界各国和地区经济发展。从 某种程度上说, 经济区域化是经济全球化的产物, 同时, 世界多极化发展趋势为经济区域化奠定了基础。在全球化 背景下, 各个国家和地区为了加强自身实力, 提升在国际 竞争中的地位, 都不失时机地推进区域经济竞争与合作, 如扩展与他国的贸易、投资合作, 最大限度发挥本国的比 较优势, 积极加入区域性经济合作组织。欧洲联盟、北美 自由贸易区和亚太经合组织等等, 都是区域竞争与合作、 经济区域化的历史结果。

在全球区域竞争日趋激烈的情况下，2010年1月1日， 中国-东盟自由贸易区正式启动, 这标志着世界上人口最 多、规模列位第三、由发展中国家组成的自由贸易区在亚 洲诞生。有关数据显示, 中国-东盟自由贸易区拥有 19 亿 消费者、近 6 万亿美元GDP和 4.5 万亿美元贸易总额, 贸易 占到世界贸易的 $13 \%$, 由中国和东盟 10 个国家共同组成。 区域内逐步消除关税壁垒、实现零关税政策, 为各个国家 乃至整个亚洲经济竞争能力的提升, 提供了良好的制度框 架保障。总而言之, 经济全球化从未间断, 区域分化与整 合也不会停息, 区域竞争只会愈来愈激烈。显然, 中国与 东南亚国家也不可避免地卷入了经济全球化与区域化的
新竞争。对于滇、桂、越来说, 也只有以积极的姿态融入, 才能在竞合中占据有利位置。

\section{2. 融入国际区域合作发展新框架}

中国-东盟自由贸易区为中国与东南亚国家经济合作 奠定了基本框架。2000年11月, 朱镕基总理提出建立中国 -东盟自贸区的设想, 2002 年11月 4 日, 中国与东盟签署了

《中国-东盟全面经济合作框架协议》，2004年11月，双 方签署自贸区《货物贸易协议》，并于2005年7月开始相 互实施全面降税。2007年1月，双方又签署了自贸区《服 务贸易协议》，已于 2007 年7 月起正式生效, 2010 年全 面建成中国-东盟自贸区, 至此, 中国与东南亚地区国际 区域合作新框架基本形成。泛红河流域处于这一自贸区域 内, 泛红河流域地区发展是对中国-东盟自贸基本合作框 架的补充与细化, 注重流域经济开发与发展, 将为山水相 邻国家的经济合作增添新元素。流域经济是一种以自然河 流水系为基础, 流域人、财、物资源配置为核心的亚区域 和跨区域经济系统。[3]20世纪30年代, 美国田纳西河流 域成功开发, 为流域经济的发展树立了仿效典范, 流域经 济的重要性受到关注, 印度的达莫达尔河, 日本的北上川 流域开发都是以田纳河流域开发为样板。[3] 流域开发强 调河流上下游、支干流之间的联系, 并以水资源最充分合 理利用为中心, 以发展流域经济为主要目标的自然、经济、 社会多因素多目标综合性区域开发。[3]泛红河流域经济 发展更多的是强调区域内经济紧密相联, 区域产业分工与 布局、区域基础设施的发展和协调，并利用区域政策融入 自贸区, 并不以水资源充分利用为中心。同时, 泛红河流 域地区主要是一个经济区域概念, 这反映在该区域在社会 经济发展中的相互关联, 并将以各地区自然资源和生产要 素的禀赋条件为基础, 形成优势互补、共同发展的流域经 济和产业分工机制和体系。

\section{3. 构建中国西南地区与东南亚区域发展新格局}

早在1992年, 在亚洲开发银行的倡议下, 大涺公河次 区域（GMS）计划形成，大涺公河次区域指涺公河流域的 6 个国家和地区, 包括束埔寨、越南、老挝、缅甸、泰国和 中国云南、广西。根据计划, 已经确定的 7 个潜力合作领 域是: 交通、通讯、能源、旅游、贸易和投资、发展人力 资源、环境保护。2006年，除了贸易和投资，新增加了农 业, 合作领域扩大到 8 个。[4]应该注意到, 农业是大涺公 河次区域经济合作计划下的优先领域之一, 诚然, 这对于 解决大涺公河次区域成员国农村地区的贫困问题起着十 分重要的作用。但从流域经济的视角来看, 大涺公河次区 域主要带动沿浀公河流域的发展, 并不能完全辐射其他国 际河流区域。

中国西南地区与东南亚国家也存在其他区域合作。 2004年, 中国与越南达成构建 “两廊一圈” 后, 开发运输 基础设施建设是首要考虑因素, 也涉及到中越贸易、投资、 技术合作、旅游、跨国界经济交流合作等。随着中国一东 盟自由贸易区建设步伐的加快和亚洲经济区域一体化的 不断发展, 如今中越边境贸易的地位已是不容忽视。中越 经贸合作始终处在一个快速发展的阶段。目前已基本形成 
了“全方位、宽领域、多层次” 全面发展的合作格局。中 越 “两廊一圈”, 即 “昆明-老街-河内-海防-广宁”、“南 宁-谅山-河内-海防-广宁” 两条经济走廊和 “环北部湾经 济圈”。“两廊一圈” 的次区域经济合作在中国-东盟自 由贸易区内既存在着一定独立性, 又与中国-东盟自由贸 易区存在着依赖关系。[5]有学者发现, 在 “两廊” 的安 排上呈 “Y” 字型分布, 结合点是越南的首都河内, 中国 的两个端点分别是昆明和南宁。河内成为两廊的枢纽, 甚 至成为聚集经济能量的 “两廊一圈” 次区域合作的重心。 因此, 防止 “两廊一圈” 内的中国的其它相关地区被边缘 化, 丧失自己应有的经济利益。[5]泛红河流域经济地区 发展, 将弥补大湄公河次区域发展领域的不足, 在地理区 域上呈现东西互动互补之势, 也将中越社会经济关系通过 红河流域进一步联结起来, 形成共同发展、利益协调共享 的机制。加快泛红河流域发展是实现中国西南地区与东南 亚区域协调发展的重要举措。

\section{3. 加快泛红河流域发展的基础和条件}

泛红河流域的国家主要是发展国家, 在许多方面存在 广泛的共同利益, 对经济发展有着稳定和增长的共同愿望。 就中越关系而言, 越共总书记农德孟曾经说过: 我们可以 找新的伙伴, 但我们不能找新的邻居。[6]泛红河流域的 发展主要涉及中越两国, 中越经济贸易关系、竞争合作现 状等等, 都构成加快泛红河流域发展的基础。

\section{1. 总体政治经济形势有利于泛红河流域的发展}

受美国金融危机的影响, 中国与东南亚各国经济遭遇 一定困难, 但政治经济形势总体保持平稳, 各国依然把经 济发展作为国家头等大事来抓。以中越为例, 直到 2009 年上半年, 越南的通货膨胀率和贸易赤字仍保持较高水平。 越南出口市场继续出现萎缩, 外来投资减少, 工业、农业、 水产业以及出口等方面的增长速度受到严重影响, 均未达 到计划指标。为了应对危机, 越南政府开始实施遏制经济 衰退、稳定宏观经济和保障社会民生等措施, 政策取得成 效, 社会发展相对稳定, 2009年越南GDP增长5.32\%。[6] 金融危机也波及中国经济, 使外需减少, 内需不足, 中国 政府实施扩大内需的应对政策, 经济继续保持快速增长。 到目前金融危机已经消退, 稳定发展的社会经济形势是泛 红河流域进一步发展宏观背景和前提。

\section{2. 区域交通改善为经济贸易创造基本条件}

交通区位与基础设施建设是经济发展的前提。随着经 贸往来推进以及多方经济社会合作意识的加强, 泛红河流 域铁路、公路等交通条件不断完善, 成为支撑云南与越南 以及中越共同发展的重要载体。中越 “两廊一圈” 规划框 架中, 关涉到两国交通合作问题, 关键是共同发展中国南 宁-凉山-河内-海防以及中国云南-老街-河内两条线路的 公路交通系统。建成于1910年滇越铁路, 由于历史原因, 有一段时期中断了国际运输。滇越铁路北起云南昆明, 南 抵越南的海防港。1996年2月, 滇越铁路开始恢复国际联 运, 直接推动了云南乃至中国与越南之间双边贸易的发展,
成为中国与越南等东南亚国家开展经济技术和文化合作 的重要通道。

2006年，中国与东盟国家就达成了《泛亚铁路网政府 间协议》，标志着泛亚铁路建设迈出实质性的一步。泛亚 铁路被誉为 “黄金走廊”、“铁丝绸之路”, 其路线确定 为北部、南部、南北部和东盟 4 条。其中, 北部、南部两 条路线经过中国境内。泛亚铁路的重大意义不言自明, 它 将成为横贯亚洲大陆的铁路动脉和重要的国际通道。泛亚 铁路南部经过中国云南境内, 从新加坡起, 经马来西亚、 泰国、老挝（或柬埔寨、越南、缅甸）进入中国云南省。 云南境内的东线为玉溪至蒙自、蒙自至河口铁路, 中线为 昆明至玉溪南、玉溪南至磨憼, 西线为大理至瑞丽。东线 预计于 2012 年实现全线通车, 中线昆明至玉溪南段 110 公 里已建成, 玉溪至磨懸铁路今年已动工开建, 并于 5 年后 通车与老挝铁路相连, 西线大瑞铁路也加快建设。云南省 在加速完善泛亚铁路网的同时健全省内铁路网体系、公路 网体系, 构建中国连接东南亚、南亚的国际大通道。据新 华网称, 昆明至泰国曼谷公路, 昆明至越南河内公路, 昆 明至缅甸曼德勒、密支那公路等云南连接东盟国家的国际 大通道云南境内段, 已全部实现高等级化。

广西加快了通往越南的边境公路建设, 泛亚铁路、公 路的拉通, 广西也可借道越南走向东南亚。广西与越南有 一条铁路, 两条高等级公路相通。南友高速公路抵达友谊 关, 友谊关到河内也是高等级公路。百色至龙邦、崇左至 水口、防城至东兴路段的高速公路已经动工; 那坡经平孟 往高平、大新经硕龙往高平、龙州经水口往高平、宁明经 爱店往谅山等路段的二级公路也在进行前期准备, 将逐步 形成较为完善的边境公路网络。

\section{3. 产业资源互补有力促进了区域贸易的扩大}

区域经济发展强调区域内优势互补、资源对接, 区域 产业间形成规模经济, 降低成本, 从而扩大经贸往来。以 中越两国为例, 中越资源禀赋各具优势, 产业结构各有特 点, 互补性强, 合作潜力大。中国对越出口以劳动密集型 产品和资本密集型产品、即纺织品、钢材、成品油、机电 产品和化工产品为主, 越南出口到中国的商品以资源密集 型产品为主, 如煤炭、原油和天然橡胶等。[7] 从中国与 越南的贸易总量变化来看, 中越经贸总量不断增长, 贸易 关系进一步稳定发展, 以更宽领域的合作与发展奠定了基 础。1991年两国双边贸易只有3230万美元，2005年已达到 81.9 亿美元, 此后两国双边贸易更是大幅度增长, 中国连 续7年成为越南最大的贸易伙伴。而近几年来, 中越贸易 迅速扩大, 双边贸易额始终保持较快的增长, 2007年随着 胡锦涛访越, 这一年的双边贸易突飞猛进, 贸易总额同比 增长了 $51.9 \%$ 。而出口额是 2003 年的 3.74 倍, 短短 4 年间增 长87.2亿美元。越来越多的越南商品出现在中国市场上。 2009年虽然受国际金融危机影响, 但中越贸易额全年同比 增长 $8.16 \%$, 达到 210.48 亿美元。其中, 中国对越出口 163 亿美元, 增长 $7.8 \%$, 自越南进口 47.5 亿美元, 增长 $9.5 \%$ 。 以上三组数据同时保持增长, 在我国对本地区贸易中也是 屈指可数的。2010年, 越中贸易总额再创新高, 高达254 亿美元。2014年, 中越全年进出口总值为836. 96 亿美元, 
这一数字较 2003 年的 46.3 亿美元增长 18 倍之多, 年均增长 超过 $30 \%$ 以上, 远高于十多年来中国外贸 $18 \%$ 的年均增长水 平。有学者通过对中国西南地区与越南、新加坡、菲律宾 产业结构的比较分析, 发现中国西南地区与东盟三国的三 次产业相似度较高, 但是具体到制造业, 整体相似度偏低, 具有互补性。同时, 也认为不能满足于制造业产业之间贸 易的互补, 要发展产业内贸易, 对同一产业的产品实行差
异化生产, 发展产业内贸易。[9]从滇越经济关系来看, 滇越经济也存在互补, 如云南对越南的焦炭、钢坏等有需 求, 越南对云南的矿石等物资也有需求, 滇越铁路的畅通 降低了运输成本, 以往越南用焦炭换昆钢的铁矿。桂越经 济也有很大的互补性。越南的重工业分布在北越, 轻工业 和石化工业分布在南越。北越与广西相邻, 广西许多中小 企业及民营企业又都以轻工业为主，极容易形互补。

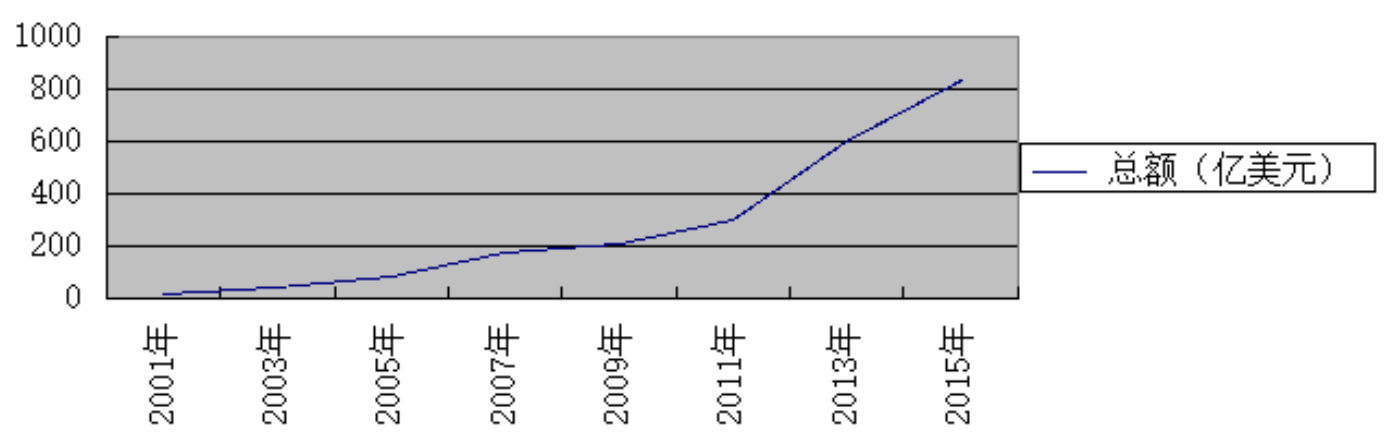

图1 中越两国历年双边贸易总额变化一览表。

\section{4. 地区经济合作实践进一步推动泛红河流域的形成}

地方推动的区域发展, 更有利于结合当地实际, 形成 适宜的发展模式。对地方经验进行总结, 取得可行性论证 后, 可以上升为国家战略层面。滇越、桂越地方政府及企 业的合作实践, 有力地推动了泛红河流经贸的发展。中越 红河公路大桥建成, 便利了中越陆路交通, 越南北部老街、 河江、莱州和奠边四省, 将与云南省共同建立跨境经济合 作区。今年, 云南省政府已与越南老街省人民委员会正式 签署《关于进一步推进中国河口-越南老街跨境经济合作 区建设的框架协议》。“中国红河一越南老街跨国经济合 作区” 的提出与践行, 将形成新的区域发展模式。具体而 言, 第一阶段, 中国河口口岸北山片区与越南老街金城商 贸区共建“中越红河商贸区”, 由中越红河公路大桥连接。 区域内以贸易物流业、金融、信息等服务业和旅游购物为 主体, 实行 “两国一区, 封闭运作, 境内关外、自由贸易” 的管理模式。第二阶段, 以中国河口口岸北山片区和红河 工业园区, 越南老街口岸经济区、腾龙工业区、贵沙矿区 共建 “中国红河一越南老街跨境经济合作区”。第三阶 段延伸发展领域, 拓展发展空间。在合作区域里, 中国争 取所有交易以人民币结算，这样就会惠及双方合作企业。 磨敗一磨丁、瑞丽一木姐跨境经济合作区项目也在积极推 进。[10]中国凭祥-越南同登以及中国东兴-越南芒街等跨 境经济合作区已相继建成和发展迅猛。

\section{4. 推进泛红河流域地区发展的主要措施}

推进泛红河流域地区发展首要的是形成一致共识, 并 且促进资本、产业、技术、人才等生产要素在区域内外的 扩散和转移, 与其他经济区域实现对接。发挥区位交通优 势, 打造物流集散中心, 形成多极化的区域发展动力机制。 最后, 加强口岸建设, 建好边境区域合作区, 发挥带动示 范效应。

\section{1. 达成泛红河流域经济发展共识}

在中国-东盟自由贸易区的框架下, 加快泛红河流域 地区的发展。近年来, “两廊一圈” 中南宁-河内-海防广宁经济走廊进展较快, 而昆明-河内一海防经济走廊进展 缓慢, 发展成效不太明显, 造成这种状况的共同原因可能 是批复手续复杂、基础设施投建、区域发展机制等问题。 昆河经济走廊也正处于泛红河流域的核心地带, 对于红河 流域的发展至关重要, 因而要加快达成泛红河流域发展的 共识, 形成新发展动力。特别是加快基础实施、体制、市 场、人才、投资环境建设, 以区域中心城市为枢纽, 建立 起发散型、快捷、便利的综合交通运输体系, 降低物流成 本, 降低交易成本, 从而降低区域内经济发展的社会成本, 在泛红河流域形成更加优良的投资环境。

\section{2. 促进要素流动、产业升级与转移, 对接其他经济区域}

泛红河流域与泛珠三角区域相连, 也与大大涺公河次 区域、两廊一圈部分重叠。在提升泛红河流域投资环境的 同时, 促进要素流动、产业升级与转移。采取适度政策措 施对接珠三角区域, 吸引珠三角和国际产业转移。在泛红 河区域内, 以区域性中心城镇为依托, 以产业园区为主体, 构建承接珠三角等区域的要素流动、产业转移的对接点与 平台, 实现产业和要素的集聚, 形成泛红河流域新的经济 增长极, 推进整个区域经济协调发展。对于各地而言, 可 以在税收、融资、土地使用等方面提供优惠政策, 更多更 好地拦引产业转移, 承接要素流动。

\section{3. 发挥区位交通优势, 打造中国与东南亚的物流集散地}

泛红河流域的中国西南地区铁路、公路、水路等交通 条件不断改善, 与东盟国家对接的大通道建设进展罗快。 广西是沿海、沿江、沿边的边疆省份, 处于泛珠江三角区 域与东盟自由贸易区两大市场的中心位置, 有便捷的出海 通道和陆路路网。云南省通往东盟国家的国际公路大通道 
初具雏形, 昆明至泰国曼谷, 昆明至越南河内, 昆明至缅 甸曼德勒、密支那公路等, 在云南境内段已全部实现高等 级化, 极大地便利了对东南亚国家的经济贸易和人员往来。 利用交通优势, 大力发展现代物流业, 打造中国与东南亚 地区的物流集散地。在边境口岸兴建物流园区, 加快物流 站场、仓储设施建设, 积极利用物联网络, 开展网上经贸 活动。利用网络进行涉外管理, 增强透明度, 提供快捷的 服务。

\section{4. 形成多极化的区域发展动力机制}

促进泛红河流域的发展, 要寻求多方面的动力, 在合 力的促动下不断发展。中央政府要创造良好的政策环境, 各地政府积极转换职能, 创造宽松的投融资环境, 如大幅 度简化民营企业跨国经营投资的审批程序。要吸引民间资 本参与，如基础设施建设中提高民间资本的份额。广西的 中小企业特别是其中的轻工业可投资越南, 形成产业互补, 促进共同发展。

\section{5. 发挥 “一带一路” 优势, 鼓励对外经贸活动}

在中国-东盟自由贸易区的框架下, 加快泛红河流域 地区的发展。充分发挥 “一带一路” 的优势, 完善边贸政 策法规, 营造良好贸易环境; 加强边贸基础设施建设; 改 善边境口岸管理体制; 文化搭台, 经济唱戏, 构筑中外边 境的经济、贸易、旅游多方面合作; 积极鼓励各种经济成 分的企业参与对外经贸活动。2015年9月, 主题为 “共建 21世纪 “海上丝绸之路” 一一共创海洋合作美好蓝图” 的 东盟峰会于广西南宁召开, 中国与东盟国家工商会共同签 署《中国一东盟法律合作共同宣言》。为积极推动多边调 解中心的建立, 双方签署《中国一东盟商事联合调解中心 协议》，在峰会框架下建立新的合作机制。

\section{6. 加强口岸建设, 建好边境区域合作区}

边境口岸是对外交往和对外贸易的重要门户，因而口 岸建设在国际合作往来方面有着重要作用与意义。泛红河 流域涉及到中越缅等国家, 加快双方边境贸易的健康发展, 口岸通畅尤为重要。加强口岸建设要求提高服务质量、工 作效率, 简化出入境手续, 以适应物流和人流不断增多的 需要。当前重点是加快电子口岸建设步伐, 进一步完善口 岸信息网络, 加快推进各地电子口岸实体平台或虚拟平台 建设, 打造一个以口岸通关执法管理为主, 逐步向相关物 流商务服务延伸的大通关、大物流、大外贸的信息化口岸。
边境区域合作区起到推动经贸发展的示范与桥梁作 用, 应加强边境区域合作, 建好现有边境合作区, 并且条 件成熟时, 将合作的范围进一步拓宽, 内容可以更广, 把 更多更大区域的贸易都吸纳进来。应不断不探索边境合作 模式, 完善各种基础设施, 特别是陆上通道和水上运输设 施的建设。

\section{致谢}

本文为国家社科基金一般项目《以国际旅游岛战略为 导向的海南农业形态构建研究》(项目批准号: 12BJY110) 的阶段性成果之一。

\section{参考文献}

[1] 陈丽晖, 丁丽勋. 国际河流流域国的合作一一以红河流域为 例 $[J]$. 世界地理研究, 2001 年第4期:65.

[2] 毛蕴诗, 戴勇. 经济全球化与经济区域化的发展趋势与特征 研究 [J]. 经济评论, 2006年第4期: 131 .

[3] 胡碧玉. 流域经济论 [D]. 四川大学博士学位论文, 2004 年: $1-2$.

[4] [越南]阮太国. GMS合作对越南中部经济发展的影响 [J].马 金案译, 东南亚纵横, 2007 年第5期: 39 .

［5］曹珂, 闩丽萍. “两廊一圈”与中国-东盟自由贸易区的关系 探析 $[J]$. 广西师范学院学报 (哲学社会科学版), 2006年7 月专刊: 83-86.

[6] 许梅. 2009年越南政治经济形势回顾与前景展望 [J]. 东南 亚研究, 2010年第2期.

[7] 皮军, 刘相骏. 中越经贸关系: 竞争性与互补性分析 $[\mathrm{J}]$. 南 洋问题研究, 2009年第2期: 50-56.

[8］和文华. 中越贸易发展现状分析 [J]. 现代经济, 2009年第7 期: 123-124.

[9] 张银银, 闵晓莹, 李立民. 中国西南地区与东盟国家产业结 构相似性分析一一以制造业为例 $[J]$. 东南亚纵横, 2007年 第7期: $16-20$.

[10] 姚诚等. 中越跨境合作框架协议今日签订 $[\mathrm{N}]$. 云南信息 报, 2010年6月8日:A4-A5. 